\title{
Screen use among young children in a city of Argentina
}

\author{
Ingrid Waisman, M.D. ${ }^{a}$, Elisa Hidalgo, M.D. ${ }^{a}$ and María L. Rossi, M.D. ${ }^{a}$
}

\begin{abstract}
The use of mobile devices has become ubiquitous in the family, across all social strata, and from an early age.

Objectives: To assess the use of mobile and fixed screens among young children, the time spent doing traditional childhood activities, and the relationship to the maternal level of education. Material and methods: Descriptive, crosssectional design.

Population: Children aged 6 months to 5 years seen in Río Cuarto, Córdoba, between July and September 2016.
\end{abstract}

Outcome measures: Demographics, family income, age at initiation, frequency of use, daily minutes, other activities.

Results: 160 surveys were included; 99\% of households had a TV and $98.75 \%$, a smartphone. among lower income households: 5.1 (standard deviation [SD]: 1.57); and among higher income households: 6.32 (SD: 1.18) $(p=0.0000)$.

By the age of $2,80.3 \%$ of children watched TV and $37.4 \%$ used touchscreen devices with help. Between 2 and 4 years old, $38.7 \%$ used screens without help.

Also, 93\% of children watched TV and 56\% used mobile screens very frequently. Children watched TV for an average of 75.6 daily minutes and used other screens for 31.3 minutes, whereas reading only accounted for 20.4 minutes.

Mothers who had completed tertiary education spent more time reading books than those who had completed primary or secondary education (analysis of variance: $p=0.00007$ ).

Conclusions: Household technological equipment is practically universal; children's exposure to screens starts at an early age. TV is the most commonly used screen although mobile screens take up a significant time. Mothers who had completed higher education spent more time reading.

a. Neoclínica, Río Cuarto, Province of Córdoba.

E-mail address:

Ingrid Waisman, M.D. ingridwaisman@arnet. com.ar

\section{Funding:}

None.

Conflict of interest:

None.

Received: 3-22-2017

Accepted: 9-4-2017

To cite: Waisman I, Hidalgo E, Rossi ML. Screen use among young children in a city of Argentina. Arch Argent Pediatr 2018;116(2):e186-e195. Average number of electronic devices: 5.68;

\author{
"So much solitude, \\ everyone's connected, \\ screen children, \\ welcome to the market." \\ (Popular song, \\ lyrics by Andrés Ciro Martínez)
}

\section{INTRODUCTION}

The impact of technology in the life of men is continuously increasing and children are no strangers to this reality. For more than 40 years, traditional media such as TV and radio have occupied a predominant place in everyday family activities; however, in recent years, with the emergence of tablets and smartphones, the ways in which we communicate, exchange information, and look for entertainment have changed. Using mobile and touchscreen devices has become ubiquitous, in general regardless of the family financial or social status. The screen culture has extended across and pervaded all social classes, and children start using these devices at an increasingly younger age. ${ }^{1,2}$

Mobile devices are unquestionably attractive: they are portable, helpful for parents to keep their children entertained whenever they need to complete their tasks, they grant access to countless sources of entertainment and information, and represent a relative cost reduction. ${ }^{3}$ For better or worse, children have access to all types of screens at an increasingly younger age and, although this tendency seems inevitable, the advantages and disadvantages of such early contact are still unclear.

Young children could play or get entertained with adequately-designed TV shows or interactive media, but they require guidance and interaction 
with adults in order to learn from screen use. ${ }^{4}$

Screen exposure has disadvantages for children. The most relevant ones are its association with sedentary habits and obesity, decreased sleep hours, potentially diminished social interaction skills, a negative impact on certain behavioral traits, and exposure to inappropriate content. ${ }^{5}$

It is also worth considering that children spend less time doing other activities, such as reading books with their parents, doing outdoor activities, and having interpersonal relationships.

It is interesting to focus on early childhood, before children start using social media, because during this stage they develop habits related to media use for future life; also at this age, parents play an important role in children's relationship with the media. This is a period of considerable brain plasticity, during which experiences have dramatic impacts on social, cognitive, and emotional development, and health-related routines, such as eating, sleeping, and doing physical activity, become established. ${ }^{4}$

There are several epidemiological studies and regulations in relation to screen use among young children in developed countries, ${ }^{3-8}$ but no similar approach in this age group has been found in Latin America or Argentina.

The objective of this study was to assess the use of mobile and fixed screens among young children in a city of Argentina, the time spent doing traditional childhood activities, and the relationship to the maternal level of education.

\section{MATERIAL AND METHODS}

Design. Observational, descriptive, prospective, and cross-sectional study.

Population. Patients aged 6 months to 4 years, 11 months and 29 days, and their mothers, seen at the outpatient offices of Neoclínica, Río Cuarto, Córdoba, between July and September 2016.

The study site is a clinic for patients who have health care coverage through a social insurance program or a managed care organization, specially focused on mother and child health. It has a pediatric hospitalization unit, a neonatology hospitalization unit, a Department of Obstetrics and Gynecology, and other specialties. The outpatient facilities of the Department of Pediatrics are located in an exclusive building and include general pediatrics offices, pediatric specialties offices, and an Emergency Department.

Sample size. For an estimated prevalence of touchscreen use of $50 \%$, the statistical test indicated that the sample should include 159 surveys.

Inclusion criteria: Patients aged 6 months to 4 years, 11 months and 29 days seen at the outpatient facilities of the Department of Pediatrics or the Emergency Department.

Exclusion criteria: Children with neurological problems or any other kind of disability.

\section{Methods}

A survey with close-ended questions was designed and adapted from the Common Sense Media survey. ${ }^{6}$ Mothers were invited to participate and their consent was obtained with their signature on the form (Annex 1).

During May 2016, a pilot survey was administered to 15 mothers and some questions were corrected because they were unclear.

\section{Outcome measures}

Children's age, mother's age, and maternal level of education. Incomplete secondary education was defined as less than 12 years of education; complete secondary education, as 1216 years of education; and complete university education, as 17 or more years of education.

Family income: less than ARS 20000 per month, ARS 20000 or more per month.

Electronic devices at home: TV, computer, tablet, smartphone, video game console (none, one, two or more).

Age at which the child started using screens with and without help: $<1$ year old, 1-2 years old, 2-3 years old, 3-4 years old, $>4$ years old.

Frequency of weekly use: never, once a week, several times a week, every day. Frequency was established for each screen and for all screens together, and also for other activities: reading, outdoors, other types of games. This outcome measure was dichotomized into infrequent (never or once a week) and frequent (several times a week, every day).

Weekly use score. The following was considered for this score: 1) TV, tablet, and smartphone use; 2 ) outdoors, reading, and other role-playing games.

Never (0 points), once a week (2 points), several times a week (4 points), every day (6 points), to establish mean and median values.

Daily minutes: TV, touchscreen (tablet and smartphone), story reading.

Analysis: an Excel database was designed and data were analyzed using the Epi Info 7.1.4.0 software, provided by the Centers for Disease 
Control and Prevention (CDC).

Numerical outcome measures were analyzed by comparison of averages and ratios using a Z-test and an analysis of variance (ANOVA); a value $<0.05$ was considered significant.

Odds ratios were estimated to demonstrate the association among qualitative outcome measures, considering a $95 \%$ confidence level.

\section{RESULTS}

Surveys completed by the mothers were included in consecutive order. No mother refused to take part. A total of 160 surveys were completed. The male: female ratio of children was 1:1.

\section{General data}

Table 1 shows the demographic characteristics of mothers and their children.

The family income was below $\$ 20000$ for 93 survey respondents $(58.1 \%)$ and $\$ 20000$ or more for $67(41.8 \%)$.

Most households (99\%) had a TV; among these, $76.8 \%$ had 2 or more. Also, $75.6 \%$ of households had one or two computers, $98.75 \%$ had a smartphone, and most families had 2 or more devices.
The average number of electronic devices per household was 5.68. The mean number was 5.1 (standard deviation [SD]: 1.57) among lower income households and 6.32 (SD: 1.18) among higher income ones. The difference was significant $(p=0.0000)$.

\section{Frequency and duration of use. Comparison to other activities}

The percentage of time that children devoted to each of the following three activities (TV, tablet/smartphone, and reading) per week is shown in Table 2.

For Table 3, scores were added and mean and median values of weekly screen use (TV, tablet, and smartphone) were estimated and compared to the scores of all other leisure activities (reading, outdoor activities, and other games).

The correlation between screen use and other activities are shown in Table 4.

Table 5 compares the weekly time spent watching TV, reading, and using other screens.

As regards screen exposure, $93 \%$ of children watched TV very frequently and $56 \%$ used mobile screens also very frequently. "Very frequent" was defined as use every day or several times a week.

TABle 1. Demographic data $(\mathrm{N}=160)$

\begin{tabular}{|c|c|c|c|c|c|}
\hline & & & & Frequency & Percentage \\
\hline \multirow[t]{7}{*}{ Children } & Age groups & $\mathrm{A}$ & 6-11 m. & 16 & 10 \\
\hline & & B & $12-23 \mathrm{~m}$. & 38 & 23.7 \\
\hline & & $\mathrm{C}$ & 24-35 m. & 39 & 24.4 \\
\hline & & $\mathrm{D}$ & $36-47 \mathrm{~m}$. & 36 & 22.5 \\
\hline & & $\mathrm{E}$ & $48-59 \mathrm{~m}$. & 31 & 19.4 \\
\hline & Age in months & Mean & SD & Mean & Range \\
\hline & & 31.3 & 14.29 & 30.5 & $6-59$ \\
\hline \multirow[t]{2}{*}{ Mothers } & Age in years & 30.16 & 5.54 & 31 & $18-45$ \\
\hline & & 13.43 & 4.06 & 13 & $6-22$ \\
\hline
\end{tabular}

SD: standard deviation; m.: months old.

TABLE 2. Percentage of time spent doing different activities per week

\begin{tabular}{lccccc}
\hline & \multicolumn{4}{c}{ Frequency } \\
\cline { 2 - 5 } & Every day & Several times a week & Once a week & Never & 3 \\
TV & 77 & 17 & 3 & 32 & 100 \\
Screens & 34 & 22 & 12 & 100 \\
Books & 25 & 38 & 16 & 100 \\
\hline
\end{tabular}

TABLE 3. Weekly screen use score compared to other activities

\begin{tabular}{lccccccccc}
\hline & Observations & Total & Mean & SD & Min. & 25\% & Mean & 75\% & Max. \\
\hline TV, tablet, smartphone & 160 & 1644 & 10.275 & 3.79 & 0 & 8 & 10 & 12 & 18 \\
Outdoors, games, and books & 160 & 1936 & 12.1 & 4.0859 & 0 & 10 & 12 & 16 & 18 \\
\hline
\end{tabular}

SD: standard deviation. 
When measured in minutes, children watched TV for an average of 75.6 daily minutes and used other screens for 31.3 minutes, whereas reading only accounted for 20.4 minutes.

\section{Screen use in relation to age}

Before 2 years old, $80.3 \%$ of children watched TV with the help of their parents and $37.4 \%$ used touchscreen devices (tablet or smartphone) also with help.

Between 2 and 4 years old, 28.7\% were able to watch TV without help and $38.7 \%$ used touchscreen devices also without help.

The weekly distribution of time was analyzed based on the age of children included in the sample. The frequency of weekly use of TV, mobile screens, and books by age is shown in Figure 1.

Table 6 shows the minutes spent the previous day watching TV, using other screens, and reading books by age group $(<2$ years old or $\geq 2$ years old).

\section{Reading and maternal level of education}

The median and SD of the weekly scores for book reading were $2.16 \pm 2.1$, respectively, among children whose mothers had completed primary education or had not completed secondary education; $3.51 \pm 2.1$, respectively, among those whose mothers had completed secondary education; and $4.12 \pm 1.5$, respectively, among those whose mothers had completed university education. The ANOVA showed a $p$ value of 0.00007 .

\section{DISCUSSION}

According to the demographic data, the study population belonged to a middle-class socioeconomic status, mothers had a middle to middle-high level of education, and practically all households had a TV and other screens. Although the difference between high- and low-income households in relation to electronic devices was significant, almost all households had a TV and a smartphone.

TV exposure was always higher than exposure to other activities, followed by mobile screen exposure. Once the scores of all leisure activities not related to screen use were added, they were slightly above screen use; however, it should be noted that participants were in a very young age group who did not attend school and for whom games, outdoor activities, and reading/ listening to stories took up a great part of their daily routine.

The greater time spent using screens did not correlate to the time spent doing other activities, so it is believed that there is no direct relationship between these outcome measures.

Consistent with what other authors have reported, ${ }^{3,7,8}$ we observed that screen exposure was almost universal and that children acquired skills for using screens at a very early age.

In a study carried out by the Subcommittee of Information and Communication Technologies of the Argentine Society of Pediatrics (Sociedad Argentina de Pediatría, SAP) between 2007 and 2008 , children older than 4 years and adolescents were assessed. It was observed that half of

TABle 4. Correlation coefficient

\begin{tabular}{lcc}
\hline Outcome measure 1 & Outcome measure 2 & Correlation coefficient \\
\hline All screens $\left(^{*}\right)$ & All other activities $\left(^{* *}\right)$ & 0.00016246 \\
TV & Reading & 0.00274 \\
TV & Outdoor activities & 0.0373 \\
\hline
\end{tabular}

$\left.{ }^{*}\right) \mathrm{TV}$, tablets and smartphones.

$\left.{ }^{* *}\right)$ Outdoors, reading, and other role-playing games.

TABLE 5. Weekly TV use compared to reading and other screen use

\begin{tabular}{lcccc}
\hline & Very frequent & Infrequent & OR & $P$ \\
\hline TV & 150 & 10 & $8.76(4.2-17.9)$ & 0.0000 \\
Books & 101 & 59 & $11.66(5.7-23.7)$ & 0.0000 \\
Other screens & 90 & 70 & & \\
\hline
\end{tabular}

OR: odds ratio. 
children accessed the Internet every day and less than half of them were supervised by a responsible adult who could monitor the content or the contacts to which they were exposed. At that time, the Group recommended that parents should become involved in their children's access to the web, encourage a fluid dialog, and foster the establishment of consensual rules, leading by example. ${ }^{9}$ The subsequent introduction of tablets and smartphones into the market has refreshed and confirmed such recommendation and extended it to include younger children.

In 2011, the American Academy of Pediatrics (AAP) made a recommendation not to allow the use of mobile screens before the age of 2, which was generally adopted by pediatricians but does not look realistic today..$^{10}$ In November 2016, the AAP recommended, for this age group, that good judgment be used to decide on exposure duration and, basically, that parents or caregivers should supervise and monitor use. ${ }^{11}$

Considering the weekly frequency observed in our study, TV use remained constant across all age groups, whereas mobile screen use increased with age. However, once the daily minutes of TV exposure were analyzed, it was observed that as children grew older, TV exposure was higher. Such contradictory information may be explained by the fact that younger children have a shorter attention span: although they frequently watch $\mathrm{TV}$, the duration of such activity is shorter.

Very young children go through a sensorimotor development stage and their understanding of screens' two-dimensional content is limited. It is believed that, in children younger than 2 years, attention control and symbolic thinking are not mature enough for them to transfer knowledge from a screen to three-dimensional real life., ${ }^{4,1}$

Before two years old, children develop sensory, cognitive, and language skills; this calls for them to explore the world around them and to interact adequately with their parents or caregivers to reach maturity successfully. ${ }^{5}$ It is not clear how the generalized use of touchscreen devices affects such maturation processes but different authors agree on the need for adults to monitor the process, select content, and limit exposure duration. ${ }^{3,4,11,12}$

According to the AAP, the industry has targeted the 0-2-year-old group (and their parents) as key consumers of electronic media. TV shows, videos, and music have been specifically developed for this age group. At present, most parents indicate that their children younger than 2 years use some sort of electronic device. ${ }^{7,11}$

Fixed and mobile screens are neither good nor bad. In the age group analyzed in this study, the

FIGURE 1. Frequency of weekly use by age (score)

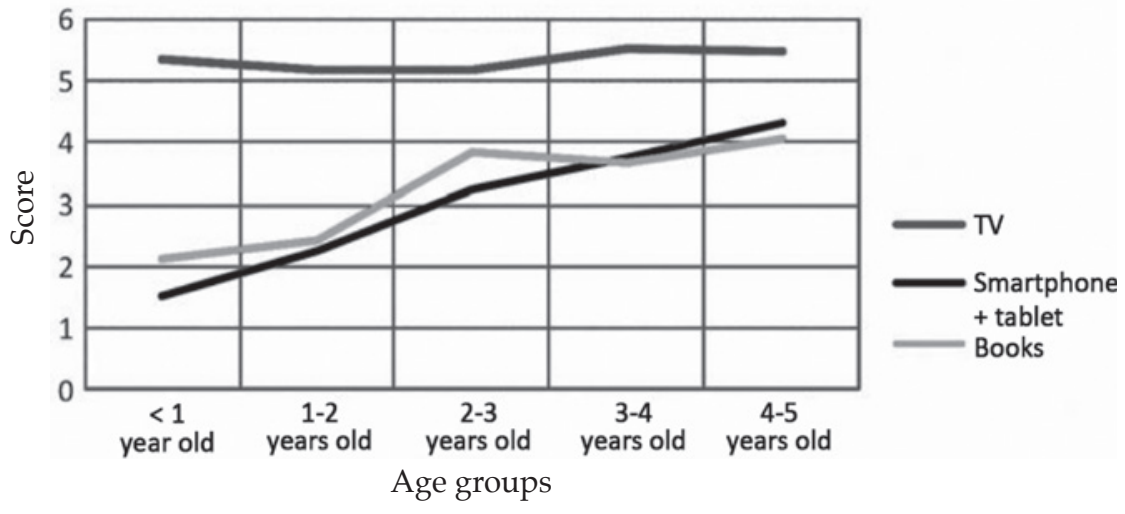

TABLE 6. Daily minutes spent watching $T V$, using other screen and reading books by age group

\begin{tabular}{lcccc}
\hline & \multicolumn{2}{c}{$<$ 2 years old } & \multicolumn{2}{c}{$\geq 2$ years old or older } \\
\cline { 2 - 5 } & Mean (SD) & Median (range) & Mean (SD) & Median (range) \\
\hline TV & $46.66(45.5)$ & $30(0-180)$ & $90.28(60.6)$ & $60(0-180)$ \\
Other screens & $16.34(34.4)$ & $0(0-150)$ & $39.1(47)$ & $20(0-150)$ \\
Books & $13.14(31)$ & $0(0-150)$ & $24.05(35)$ & $20(0-150)$ \\
\hline
\end{tabular}

SD: standard deviation. 
difference lies in how parents use screens, how they introduce technology to their children, and how they protect them from potential risks. ${ }^{1}$

In turn, an excessive use of mobile devices by parents has been associated with a lower level of verbal and non-verbal family interaction, which may lead to parent-child conflicts. ${ }^{4,5,13}$

For this reason, the SAP's Subcommittee of Information and Communication Technologies has recently proposed that the pediatric community should promote the "no screens at the dinner table" 2 campaign to increase direct, personal interaction during a sensitive time for the family.

Other authors ${ }^{3}$ have referred to children owning different electronic devices. In our setting, it has been observed that families share TV and tablets and, very especially, smartphones. Although these are not owned by young children, they are widely available.

Asking parents to read a book or listening to a story are activities that are undoubtedly set aside by technological innovations. However, it was observed that mothers who had a higher level of education spent more time telling stories or reading books to their young children.

The limitations of this study are, on the one side, that participants belonged to a rather homogeneous middle-class socioeconomic status whose mothers had a high level of education, so it is difficult to extrapolate these outcomes to the general population. ${ }^{3}$ On the other side, several answers may include a recall bias, especially those related to the history of electronic device use according to children's age. In addition, and consistent with the concern expressed by other authors, ${ }^{14}$ answers were based on maternal perception, not on objective measurements.

This study does not aim at elucidating the effect of TV or mobile screens on the growth of children younger than 5 years; it merely proposes to describe the situation in Argentina, which, despite having its own characteristics, is rather similar to the worldwide reality, and to attract pediatricians' attention because it is at this age that children's behavior patterns are shaped for the future, not only in relation to digital media use but also to many aspects of their life and health.

Pediatricians may become an adequate source of information for parents by discussing the results of studies, offering recommendations to accompany children during screen use, and advising how to regulate exposure duration.

\section{Acknowledgments}

We would like to thank Paula Otero, M.D., for reading the manuscript and making such valuable suggestions.

\section{REFERENCES}

1. Gutnick AL, Robb M, Takeuchi L, et al. Always connected: The new digital media habits of young children. New York: The Joan Ganz Cooney Center at Sesame Workshop; 2010. [Accessed on: September $\left.6^{\text {th }}, 2017\right]$. Available at: http: / / www.joanganzcooneycenter.org/wp-content / uploads/2011/03/jgcc_alwaysconnected.pdf.

2. Campaña \#Cena sin Pantallas. Asociación Chicos.net. Tecnología para un Mundo Mejor. 2. ${ }^{a}$ ed. [Accessed on: September $\left.6^{\text {th }}, 2017\right]$. Available at http://www.chicos. net/2016/ cenasinpantallas/.

3. Kabali HK, Irigoyen M, Nunez-Davis R, et al. Exposure and Use of Mobile Media Devices by Young Children. Pediatrics. 2015;136(6):1044-50.

4. Radesky JS, Christakis DA. Increased Screen Time: Implications for Early Childhood Development and Behavior. Pediatr Clin North Am 2016;63(5):827-39.

5. Reid Chassiakos Y, Radesky J, Christakis D, et al. Children and Adolescents and Digital Media. Pediatrics 2016:138(5):e20162593.

6. Rideout V, Saphir M, Pai S, et al. Zero to Eight: children's media use in America 2013. Common Sense Media Research Study. [Accessed on: September $6^{\text {th }}, 2017$ ]. Available at: https: / / www.commonsensemedia.org/research / zeroto-eight-childrens-media-use-inamerica-2013.

7. Chandra M, Jalaludin B, Woolfender S, et al. Screen time of infants in Sydney, Australia: a birth cohort study. BMJ Open.2016;6(10):e012342.

8. Ahearne C, Dilworth S, Rollings R, et al. Touch-screen technology usage in toddlers. Arch Dis Child 2016;101(2): 181-3.

9. Grupo de informática de la Sociedad Argentina de Pediatría. Resultado de la encuesta "Internet en los hogares". [Accessed on: September 6 ${ }^{\text {th }}, 2017$ ]. Available at:http: / /www.sap.org.ar/docs / organizacion/Grupos/ informatica/encuesta.pdf.

10. Council on Communications and Media, Brown A. Media Use by Children Younger Than 2 Years. Pediatrics 2011;128(5):1040-5.

11. Kostyrka-Allchorne K, Cooper N R, Simpson A. Touchscreen generation: children's current media use, parental supervision methods and attitudes towards contemporary media. Acta Paediatr 2017;106(4):654-62.

12. Linebarger DL, Barr R, Lapierre MA, et al. Associations between parenting, media use, cumulative risk, and children's executive functioning. J Dev Behav Pediatr 2014;35(6):367-77.

13. Richard G. Los niños frente a las pantallas. Boletín Especial Día del Niño. Universidad Católica de Córdoba, 2016. [Accessed on: September $6^{\text {th }}$, 2017]. Available at: http:/ / www2.ucc.edu.ar / especiales / los-ninos-frente-a-laspantallas/.

14. Goh SN, Teh LH, Tay WR, et al. Sociodemographic, home environment and parental influences on total and devicespecific screen viewing in children aged 2 years and below: an observational study. BMJ Open. 2016;6(1):e009113. 
e192 / Arch Argent Pediatr 2018;116(2):e186-e195 / Original article

\section{ANNEX 1}

Survey

Survey no.

Child's first name and initial of last name:

1) Demographic data

\begin{tabular}{|l|l|l|}
\hline & Years old & Months old \\
\hline Age & & \\
\hline Sex & F & M \\
\hline Birth order & & Singleton \\
\hline
\end{tabular}

\begin{tabular}{|l|l|l|l|}
\hline & Mother & Father & \\
\hline Age & & & \\
\hline Years of education & & & \\
\hline Working outside the home? & & & \\
\hline Number of children & & & \\
\hline $\begin{array}{l}\text { Do you have Internet access } \\
\text { at home? }\end{array}$ & YES & NO & \\
\hline Family income & $<20000$ & $20000-40000$ & $>40000$ \\
\hline
\end{tabular}

2) Screens at home

Which of the following devices (if any) do you have at home?

\begin{tabular}{|l|l|l|l|}
\hline & None & 1 & 2 or more \\
\hline \multicolumn{1}{|c|}{ TV } & & & \\
\hline Mobile phone & & & \\
\hline Computer & & & \\
\hline Mobile devices (tablet, iPod) & & & \\
\hline Video game console & & & \\
\hline Other & & & \\
\hline
\end{tabular}

3) Which of the following devices does the child have in his/her own bedroom?

\begin{tabular}{|l|l|l|}
\hline Device & YES & NO \\
\hline TV & & \\
\hline Computer or netbook & & \\
\hline Video game console & & \\
\hline Other & & \\
\hline & & \\
\hline
\end{tabular}


4) Which of the following devices (if any) does the child own? Even if it is not his/her property, he/she may use it whenever he/she wants to.

\begin{tabular}{|l|l|l|}
\hline Device & YES & NO \\
\hline TV & & \\
\hline Computer or netbook & & \\
\hline Video game console & & \\
\hline Tablet & & \\
\hline Mobile phone & & \\
\hline Other & & \\
\hline
\end{tabular}

5) How old was the child when he/she started...?

\begin{tabular}{|c|c|c|c|c|c|c|c|c|c|c|}
\hline \multirow[t]{2}{*}{ Activity } & \multicolumn{4}{|c|}{ With help } & \multicolumn{3}{|c|}{ Alone } & \multirow[b]{2}{*}{2 y.o. } & \multirow[b]{2}{*}{3 у.о. } & \multirow[b]{2}{*}{4 y.o. } \\
\hline & $<1$ y.o. & 1 y.o. & 2 y.o. & 3 y.o. & 4 y.o. & $<1$ y.o & 1 y.o. & & & \\
\hline \multicolumn{11}{|l|}{ Watching TV } \\
\hline \multicolumn{11}{|l|}{ Using touchscreens } \\
\hline \multicolumn{11}{|l|}{$\begin{array}{l}\text { Calling someone on } \\
\text { the phone or } \\
\text { making a videocall }\end{array}$} \\
\hline \multicolumn{11}{|l|}{ Playing video games } \\
\hline \multicolumn{11}{|l|}{ Surfing the Internet } \\
\hline Using apps & & & & & & & & & & \\
\hline
\end{tabular}

y.o.: years old.

6) How many and which apps does the child use (with or without help)?

Number:

App names (that you recall):

7) How often does the child do the following activities?

\begin{tabular}{|l|l|l|l|l|}
\hline Activity & Never & Once a week & $\begin{array}{l}\text { Several times } \\
\text { a week }\end{array}$ & Every day \\
\hline Watching TV & & & & \\
\hline Using a computer & & & & \\
\hline Playing video games & & & & \\
\hline Using tablet or smartphone apps & & & & \\
\hline $\begin{array}{l}\text { Reading books or having someone } \\
\text { read to him/her }\end{array}$ & & & & \\
\hline Sports or outdoor activities & & & & \\
\hline Playing educational games or drawing & & & & \\
\hline Using educational apps & & & & \\
\hline
\end{tabular}


8) How long did the child do the following activities YESTERDAY?

\begin{tabular}{|l|l|l|l|l|l|}
\hline Activity & $<30$ minutes & 30 minutes & 1 hour & 2 hours & $\begin{array}{l}\text { More than } \\
2 \text { hours }\end{array}$ \\
\hline Watching TV & & & & & \\
\hline Using a computer & & & & & \\
\hline Playing video games & & & & & \\
\hline $\begin{array}{l}\text { Using tablet or } \\
\text { smartphone apps }\end{array}$ & & & & & \\
\hline $\begin{array}{l}\text { Reading books or having } \\
\text { someone read to him/her }\end{array}$ & & & & & \\
\hline Sports or outdoor activities & & & & & \\
\hline $\begin{array}{l}\text { Playing educational games } \\
\text { or drawing }\end{array}$ & & & & & \\
\hline Using educational apps & & & & & \\
\hline
\end{tabular}

9) While the child is doing other activities, how often is the TV on in the background?

\begin{tabular}{|l|l|l|l|l|}
\hline TV on & \multicolumn{4}{|c|}{ Frequency } \\
\hline & Never & Rarely & Often & Always \\
\hline
\end{tabular}

10) What is the purpose of using these devices?

- For the child's entertainment only

- So that parents or caregivers can complete household or work-related activities

- For the child's entertainment in public places or while traveling

- Before going to bed

- Other

11) Have you ever talked to your pediatrician about using these devices and his/her recommendations regarding children?

- YES

- NO 